\title{
A presença da Galactoquinase em Tecidos Animais ${ }^{*}$
}

\author{
Metry Bacila \\ Escola Superior de Agricultura e Veterinária do Paraná. \\ Assistente da Faculdade de Medicina da Universidade do Paraná.
}

\begin{abstract}
The author relates experimental work which lead him to conclude for the presence of galactokinase in animal tissues, explaining in this way that the first step of the galactose intermediary metabolism is its esterification, in the presence of ATP and the enzyme in question, activated by magnesium to galactose-1-phosphate.
\end{abstract}

Key Words: Galactokinase; galactose metabolism; animal tissues; galactose-1-phosphate

\section{INTRODUÇÃO}

EULER e ADLER (1935) e LUTWAK-MANN e MANN (1935) determinaram, na levedura, a presença de uma enzima capaz de catalisar a transferência de um fosfato do trifosfato de adenosina (ATP) para as hexoses, a qual foi denominada por EULER de heterofosfatase. Antes, porém, MEYERHOFF (1927) obtivera da levedura uma enzima que adicionada a extratos velhos de músculo proporcionava-lhe a recuperação da capacidade de fermentar a glicose, tendo-lhe chamado hexoquinase. Ambas as enzimas, heterofosfatase e hexoquinase são idênticas. A reação catalisada pela hexoquinase, determinada inicialmente por MEYERHOFF (1935) foi revista por COLOWICK e KALCKAR (1941) que a estabeleceram como se segue, verificando que a hexoquinase da levedura transfere apenas um fosfato para as hexoses a partir do ATP:

\footnotetext{
Trifosfato de adenosina + Glicose Difosfato de adenosina $=$ glicose- 6 -fosfato
}

Verificou-se, contudo, que a hexoquinase não tem atividade catalítica sobre a galactose.

KOSTERLITZ (1937), porém, conseguiu isolar do fígado de ratas alimentadas com galactose uma mistura de diferentes ésteres, encontrando, entre eles $25,7 \%$ de galactose-1-fosfato.

O mesmo KOSTERLITZ (1939), então com a finalidade de determinar o mecanismo enzimático de tal reação preparou sinteticamente a galactosemonofostato após ter determinado a sua estrutura (KOSTERLITZ, 1943), provavelmente um $\alpha$ piranósido, tal como o ácido glicose-1-fosfórico natural. A galactose-1-fosfato sintética que obteve é um fosforil- $\alpha$-mono-d-galacto-piranósido. Não conseguiu, entretanto, elucidar tal mecanismo.

Seguem-se, então, os trabalhos experimentais de LELOIR et al. (19--) e CAPUTTO et al. (1948) quando encontraram em citolizados de $S$. fragilis uma enzima capaz de catalisar a reação de esterificação da galactose em carbono 1, na presença do ATP e de íons $\mathrm{Mg}++$, à qual denominaram galactoquinase.

\footnotetext{
* Trabalho realizado no Instituto de Investigações Bioquímicas da Fundação Campomar (Buenos Aires).

$\wp$ Artigo publicado no Arquivos de Biologia e Tecnologia, v. 3, pp. 3-11, 1948.
} 
Posteriormente TRUCCO et al. (1948) conseguiram extratos parcialmente purificados, a partir do S. fragilis, os quais eram mais ricos em galactoquinase do que em hexoquinase, passandose o inverso com os extratos crus. Verificaram, pois, LELOIR e seus colaboradores (TRUCCO et al., 1948) que a reação catalítica da galactoquinase é a seguinte:

$$
\mathrm{ATP}+\text { galactose } \underset{\mathrm{Mg}++}{\stackrel{\text { galactoquinase }}{\longrightarrow}} \mathrm{ADP}+\text { galactose-1-fosfato }
$$

Seguindo-se esta ordem de idéias tratamos de determinar experimentalmente a presença da galactoquinase em tecidos animais.

Trabalhamos com ratas e nestas tratamos de isolar e purificar a enzima a partir de fígado e de mucosa intestinal.

Pelas investigações já citadas de KOSTERLITZ havia este preparado, a partir de ratas e coelhos alimentados com galactose, o éster galactose-1fosfato, sem, contudo, determinar o mecanismo da sua formação.

$\mathrm{O}$ achado de LELOIR e seus colaboradores da galactoquinase em extratos de $S$. fragilis e de levedura adaptada à galactose, indicava a possibilidade da existência da galactoquinase em tecidos animais.

A sua determinação viria demonstrar que a primeira fase da utilização da galactose nos animais seria a da esterificação, em carbono 1 , de um fosfato transferido do ATP, pela enzima em questão.

Para tanto tratamos de precipitar, principalmente de fígado de ratas, a galactoquinase e determinar a sua atividade em presença do ATP e da galactose e de íons $\mathrm{Mg++}$. Um sistema em que entrava o extrato $+\mathrm{ATP}+\mathrm{Mg}++$ era incubado a $30^{\circ}$ durante determinado período de tempo, ao fim do qual a reação era suspensa mediante solução a $5 \%$ de sulfato de zinco e as proteínas, o ATP e os ésteres da galactose, precipitados com hidróxido de bário. Em seguida, para verificar a galactose livre, era praticada a medida pelo método de SOMOGYI (1945) e NELSON (1944), com leitura fotocolorimétrica pelo Klett-Summerson, com filtro 52.

\section{MATERIAL E MÉTODOS}

\section{1) OBTENÇÃO DOS EXTRATOS DE ÓRGÃOS}

Trabalhamos com ratas. Inicialmente procuramos preparar extratos a partir de fígado, mucosa intestinal, músculo, cérebro e pulmão. Posteriormente, concentramos nosso trabalho exclusivamente em fígado.

Em experiências sucessivas, repetimos a extração nas condições que passamos a expor:

1. Rata alimentada a leite e lactose durante três dias. Uma hora antes de ser sacrificada recebeu $10 \mathrm{~cm}^{3}$ de solução de galactose a $5 \%$, intraperitonealmente. Fígado e intestino delgado recebidos em água gelada e triturados. Suspensão centrifugada, trabalhando-se com o sobrenadante.

2. Rata alimentada exclusivamente com galactose durante três dias. Fígado e intestino delgado recebidos em água gelada e triturados. Trabalhamos somente com fígado e mucosa intestinal. Como as determinações acusavam altas reduções, maiores do que a suposta para a galactose adicionada aos sistemas, procuramos solver o problema, trabalhando, então, como se segue.

3. Fígado de rata normal, dialisado contra água e contra galactose e uma parte fermentada com levedura. No primeiro, a redução, como era de esperar-se, aumentou muito e no segundo baixou. Neste caso, a suspensão de fígado era submetida à fermentação e, depois, centrifugada, trabalhando-se com o sobrenadante decantado.

4. Fígado triturado juntamente com levedura. O objetivo da fermentação era de destruir a glicose e evitar a formação de substâncias redutoras.

5. Como os resultados desejados não estavam sendo obtidos com segurança, e supondo tratar-se da existência de ATPase que destruísse o ATP, passamos a congelar os extratos obtidos.

6. Depois adotamos a técnica seguinte: Fígado de rata triturado e suspenso em um volume de água, filtrado em gaze. Tratamos, então, de precipitar a enzima com sulfato de amônio a meia saturação, centrifugamos de um a dois minutos e decantamos, 
ressuspendendo o precipitado em água, praticando, então, a medida da atividade.

7. Passamos, depois a congelar durante alguns dias, o fígado íntegro, com a finalidade de obter extratos mais ativos, já que o congelamento conservava muito bem a atividade dos extratos e permitia a obtenção de bons preparados. O fígado era, então, triturado, ressuspenso em um volume de água gelada, filtrado em gaze e o filtrado precipitado com sulfato de amônio a meia saturação.

8. A comprovação de que a precipitação com sulfato de amônio a meia saturação precipitava a enzima a fizemos, trabalhando, em uma das experiências que se seguiram, tanto com o precipitado como com o sobrenadante, encontrando atividade apenas no precipitado e nenhum no sobrenadante.

9. Além desta técnica, preparamos, também, extratos filtrando a Buchner com celite: fígado congelado, triturado a frio, suspenso em água, passando em gaze e depois filtrado em Buchner, com celite e o filtrado precipitado com sulfato de amônio, centrifugado, ressuspendendo em água o precipitado.

10. Experimentamos, também, precipitar com outras concentrações de sulfato de amônio, mas, o tratamento com este sal, a meia saturação foi o que melhores resultados proporcionou.

11. Como resultado dos trabalhos experimentais, estabelecemos, então, que a técnica para a extração da enzima, a partir de fígado e que melhores resultados deu foi a seguinte: - a) congelar o fígado; b) triturar a baixa temperatura (em gelo); c) suspender o triturado em um volume de água destilada, gelada; d) passar em gaze; e) precipitar com sulfato de amônio a meia saturação; f) centrifugar; g) decantar o sobrenadante; h) ressuspender o precipitado com pouco de água.

\section{2) MEDIDA DA ATIVIDADE DA ENZIMA}

Procedemos à medida da atividade dos extratos obtidos pela técnica acima, por titulação da galactose e por manometria pelo aparelho de Warburg.

a) Titulação da galactose esterificada

Com base no método de SOMOGYI (1945) e NELSON (1944), procedíamos à medida da atividade da maneira seguinte: - galactose incubada na presença de extrato, de ATP e de $\mathrm{Mg}++$, reação suspensa com sulfato de zinco e precipitação das proteínas, do ATP e dos ésteres fosfóricos com hidróxido de bário. Medida da galactose livre pelo SOMOGYI e NELSON.

Preparávamos um substrato constante de ATP, galactose e $\mathrm{Mg}++$. A galactose era usada em solução centimolar e o sulfato de magnésio, a $10 \%$. Na preparação do substrato variamos algumas vezes no referente à quantidade de ATP, mas, na maioria das vezes, em cada tubo de reação colocávamos $3 \mathrm{~cm}^{3}$ de ATP $=0,2 \mathrm{~cm}^{3}$ da solução de galactose e $0,02 \mathrm{~cm}^{3}$ da solução de sulfato de magnésio. Num tubo controle, o substrato era colocado ao final, após a suspensão da reação pelo sulfato de zinco, permanecendo, o mesmo, inicialmente, apenas com o extrato enzimático. Praticamos reações controles, também, estabelecendo, além do "tempo zero" do substrato, como correntemente fazíamos, um tempo zero de galactose e, também, de ATP.

Procedendo à medida da atividade, segundo o tempo de incubação, trabalhamos, numa das experimentações, de acordo com o esquema que se segue e obtendo os resultados nele constantes.

Após a precipitação com o hidróxido de bário, os tubos eram centrifugados e do sobrenadante retirado $1 \mathrm{~cm}^{3}$ que se passava a um tubo de ensaio marcado para $10 \mathrm{~cm}^{3}$, seguindo-se a determinação pelo SOMOGYI e NELSON. 
TABELA 1 - MEDIDA DA ATIVIDADE DA GALACTOQUINASE EM TECIDOS ANIMAIS

\begin{tabular}{|c|c|c|c|c|c|c|c|c|}
\hline Tubo & $\begin{array}{c}\text { Substrato } \\
\mathbf{c m}^{3}\end{array}$ & $\begin{array}{c}\text { Extrato } \\
\mathrm{cm}^{3}\end{array}$ & $\begin{array}{l}\text { Água } \\
\text { cm }^{3}\end{array}$ & \begin{tabular}{|c|}
$\begin{array}{c}\mathrm{ZnSO}^{4} \\
\mathbf{c m}^{3}\end{array}$ \\
\end{tabular} & \begin{tabular}{|c|}
$\begin{array}{c}\text { Substrato } \\
\mathbf{c m}^{\mathbf{3}}\end{array}$ \\
\end{tabular} & $\begin{array}{c}\mathrm{Ba}(\mathrm{OH})^{2} \\
\mathrm{~cm}^{3}\end{array}$ & Redução $\mathbf{m} \mu$ & Tempo \\
\hline 1 & 0,52 & 0,1 & 0,38 & 0,5 & - & 0,5 & 230 & 20 minutos \\
\hline $1 \mathrm{c}$ & - & 0,1 & 0,38 & 0,5 & 0,52 & 0,5 & 260 & \\
\hline 2 & 0,52 & 0,1 & 0,38 & 0,5 & - & 0,5 & 225 & 40 minutos \\
\hline $2 \mathrm{c}$ & - & 0,1 & 0,38 & 0,5 & 0,52 & 0,5 & 260 & \\
\hline 3 & 0,52 & 0,1 & 0,38 & 0,5 & - & 0,5 & 220 & 60 minutos \\
\hline $3 \mathrm{c}$ & - & 0,1 & 0,38 & 0,5 & 0,52 & 0,5 & 260 & \\
\hline 4 & 0,52 & 0,1 & 0,38 & 0,5 & - & 0,5 & 185 & 80 minutos \\
\hline $4 \mathrm{c}$ & - & 0,1 & 0,38 & 0,5 & 0,52 & 0,5 & 260 & \\
\hline 5 & 0,52 & 0,1 & 0,38 & 0,5 & - & 0,5 & 190 & 100 minutos \\
\hline $5 c$ & - & 0,1 & 0,38 & 0,5 & 0,52 & 0,5 & 270 & \\
\hline 6 & 0,52 & 0,1 & 0,38 & 0,5 & - & 0,5 & 165 & 120 minutos \\
\hline $6 c$ & - & 0,1 & 0,38 & 0,5 & 0,52 & 0,5 & 260 & \\
\hline 7 & 0,52 & 0,1 & 0,38 & 0,5 & - & 0,5 & 160 & 140 minutos \\
\hline $7 \mathrm{c}$ & - & 0,1 & 0,38 & 0,5 & 0,52 & 0,5 & 260 & \\
\hline 8 & 0,52 & 0,1 & 0,38 & 0,5 & - & 0,5 & 150 & 160 minutos \\
\hline $8 \mathrm{c}$ & - & 0,1 & 0,38 & 0,5 & 0,52 & 0,5 & 260 & \\
\hline
\end{tabular}

O cálculo da galactose esterificada é feito dividindo-se o valor da redução do tubo de reação pelo valor da redução do tubo controle, subtraindo-se, o resultado, da unidade. A seguinte curva expressa o resultado obtido.

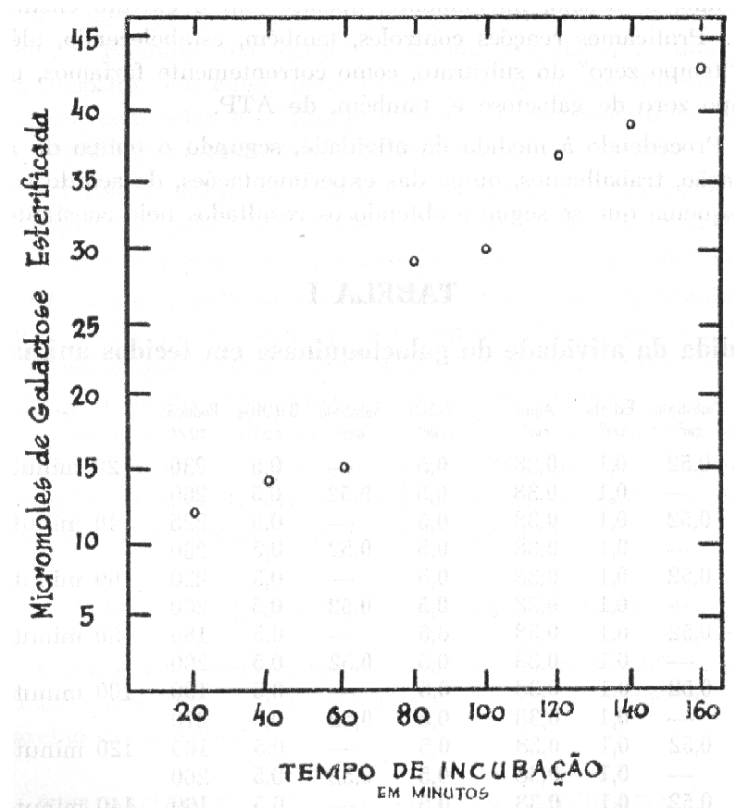

Fig. 1 - Curva da atividade, segundo o tempo de incubação da galactoquinase obtida de tecidos animais. b) Medida manométrica da atividade da galactoquinase de tecidos animais.

Esta medida foi procedida segundo a técnica empregada por COLOWICK e KALCKAR (1941) para a hexoquinase. O fundamento da mesma está em que cada molécula de galactose esterificada liberta um mol de ácido $(\mathrm{H})$ o qual atua sobre o bicarbonato anexado ao sistema, libertando $\mathrm{CO}_{2}$, cuja presença é verificada no manômetro de Warburg.

A dois frascos de Warburg, contendo toluol para evitar a proliferação bacteriana, juntamos:
Centro

Enzima

Bicarbonato

Galactose

Magnésio

Água

\section{Lateral}

ATP

Bicarbonato
1)

$0,5 \mathrm{~cm}^{3}$

$0,1 \mathrm{~cm}^{3}$

$0,2 \mathrm{~cm}^{3}$

$0,4 \mathrm{~cm}^{3}$

$46,0 \mathrm{~cm}^{3}$

1)

$0,5 \mathrm{~cm}^{3}$

$0,2 \mathrm{~cm}^{3}$
2)

$0,5 \mathrm{~cm}^{3}$

$0,1 \mathrm{~cm}^{3}$

$0,4 \mathrm{~cm}^{3}$

$48,0 \mathrm{~cm}^{3}$

\section{2)}

$0,5 \mathrm{~cm}^{3}$

$0,2 \mathrm{~cm}^{3}$
Obtivemos os seguintes resultados:
1)

$7,25 \mu \mathrm{l}$ de $\mathrm{CO}_{2}$ $20,44 \mu \mathrm{l}$ de $\mathrm{CO}_{2}$

$29,00 \mu \mathrm{lde} \mathrm{CO}_{2}$

\section{2)}

$5,84 \mu \mathrm{l}$ de $\mathrm{CO}_{2}$ $0 \mu \mathrm{lde} \mathrm{CO}_{2}$

$13,14 \mu \mathrm{l}$ de $\mathrm{CO}_{2}$ 
A curva abaixo, atesta os resultados obtidos, os quais indicam atividade enzimática do extrato obtido a partir de fígado de ratas.

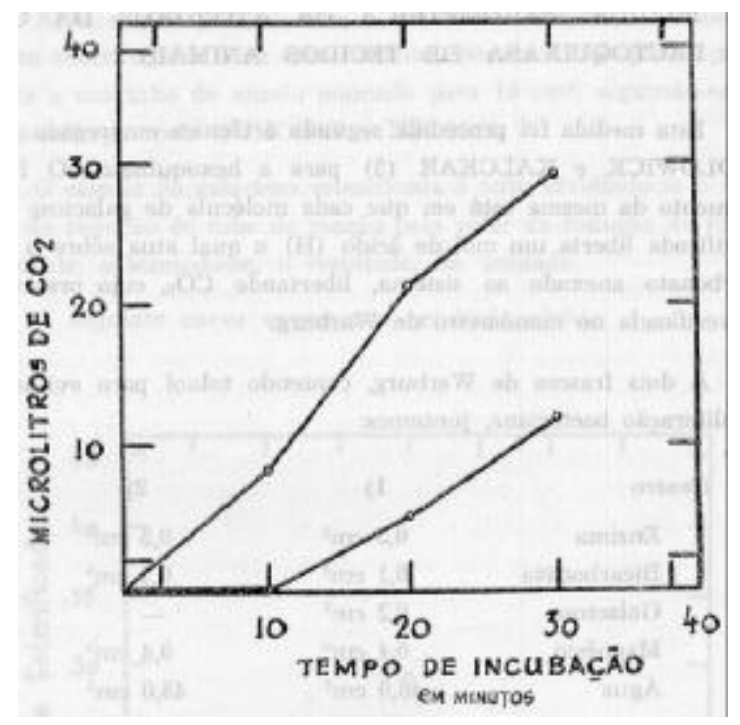

Fig. 2 - Curva manométrica da atividade da galactoquinase de tecidos animais.

Há evidente necessidade, entretanto, de procurar obter extratos mais ativos, para dar uma melhor definição da atividade enzimática da galactoquinase em tecidos animais, o que estamos buscando fazer, não só com o objetivo indicado, mas, também, com o de realizar trabalhos experimentais correlacionados com a enzima em questão e que dizem respeito ao metabolismo intermediário da galactose.

\section{RESUMO}

$\mathrm{O}$ autor relata trabalhos experimentais que o levaram a concluir pela existência da galactoquinase em tecidos animais, explicando desta maneira, que a primeira fase do metabolismo intermediário da galactose nos mesmos é a sua esterificação, em presença do ATP e da enzima em questão, ativada pelo magnésio, para galactose-1-fosfato.

\section{REFERÊNCIAS}

EULER, H. von and ADLER, E. (1935), Z. physiol. Chem. 235 : 122.

LUTWAK-MANN, C. and MANN, T. (1935), Biochem. Z., 281 : 140.

MEYERHOFF, O. (1927), Biochem. Z., 183 :176.
MEYERHOFF, O. (1935), Naturwissenschaften, 23 : 850.

COLOWICK, S. P. and KALCKAR, H. M. (1941), J. Biol. Chem., 137 : 789.

KOSTERLITZ, H. W. (1937), Biochem. J., 31 : 2217.

KOSTERLITZ, H. W. (1939), Biochem. J., 33 : 1087.

KOSTERLITZ, H. W. (1943), Biochem. J., 37 : 318.

CAPUTTO, R.; LELOIR, L. F.; TRUCCO, R. E. (1948), Enzymologia, 12 : 350.

LELOIR, L. F.; TRUCCO, R. E.; CAPUTTO, R.; MITTELMANN, N. and PALADINI, A. (19--), Estudio sobre el metabolismo de lactosa y galactosa. Apresentado ao $V$ Congresso Sul-Americano de Química reunido em Santiago.

TRUCCO, R. E.; CAPUTTO; R. LELOIR L. F. and MITTELMANN, N. (1948), Arch. of Biochem., 18 : 137.

SOMOGYI, M. (1945), J. Biol. Chem., 160 : 61.

NELSON, N. (1944), J. Biol. Chem., 153 : 375. 